\title{
Gender Differences in Gratitude: Examining Appraisals, Narratives, the Willingness to Express Emotions, and Changes in Psychological Needs
}

\author{
Todd B. Kashdan, ${ }^{1}$ Anjali Mishra, ${ }^{1}$ William E. Breen, ${ }^{1}$ and \\ Jeffrey J. Froh ${ }^{2}$ \\ ${ }^{1}$ George Mason University \\ ${ }^{2}$ Hofstra University
}

\begin{abstract}
Previous work suggests women might possess an advantage over men in experiencing and benefiting from gratitude. We examined whether women perceive and react to gratitude differently than men. In Study 1, women, compared with men, evaluated gratitude expression to be less complex, uncertain, conflicting, and more interesting and exciting. In Study 2, college students and older adults described and evaluated a recent episode when they received a gift. Women, compared with men, reported less burden and obligation and greater gratitude. Upon gift receipt, older men reported the least positive affect when their benefactors were men. In Studies 2 and 3, women endorsed higher trait gratitude compared with men. In Study 3 , over 3 months, women with greater gratitude were more likely to satisfy needs to belong and feel autonomous; gratitude had the opposite effect in men. The willingness to openly express emotions partially mediated gender differences, and effects could not be attributed to global trait affect. Results demonstrated that men were less likely to feel and express gratitude, made more critical evaluations of gratitude, and derived fewer benefits. Implications for the study and therapeutic enhancement of gratitude are discussed.
\end{abstract}

Accumulating evidence supports the idea that gratitude is linked to greater psychological and physical well-being (Emmons \& McCullough, 2004); helps build lasting, meaningful social relationships

This research was supported by National Institute of Mental Health grant MH-73937 to Todd B. Kashdan. We express our gratitude to Daniel Terhar and Kate Doherty for their assistance in data collection and preparation stages.

Correspondence concerning this article should be addressed to Todd B. Kashdan, Department of Psychology, MS 3F5, George Mason University, Fairfax, VA 22030. Email: tkashdan@gmu.edu.

Journal of Personality 77:3, June 2009

(C) 2009, Copyright the Authors

Journal compilation (C) 2009, Wiley Periodicals, Inc.

DOI: $10.1111 / \mathrm{j} .1467-6494.2009 .00562 . x$ 
(Fredrickson, 1998, 2004); serves as an evolutionary adaptation that sustains reciprocal altruism (Trivers, 1971); and is negatively related to emotional disturbances such as depression, social anxiety, and envy (Kashdan \& Breen, 2007; McCullough, Emmons, \& Tsang, 2002). Many of these associations held after controlling for Big Five personality traits and social desirability biases (McCullough et al., 2002). In addition to influencing well-being, the experience of gratitude leads people to respond prosocially toward benefactors (Bartlett \& DeSteno, 2006; Tsang, 2006, 2007) and unrelated others (Bartlett \& DeSteno, 2006), resulting in an "epidemiology of altruism" (Nowak \& Roch, 2007). Moreover, upon comparing four existing "positive psychology" interventions, gratitude interventions yielded the largest effects at posttreatment and follow-up assessments up to 1 month later (Seligman, Steen, Park, \& Peterson, 2005). The sheer magnitude of these relations and the therapeutic efficacy of gratitude interventions provide support for the value of devoting additional resources to understanding and enhancing gratitude.

Gratitude is experienced when people receive something beneficial or felt when somebody does something kind or helpful. It has been defined as "a sense of thankfulness and joy in response to receiving a gift, whether the gift be a tangible benefit from a specific other or a moment of peaceful bliss evoked by natural beauty" (Emmons, 2004, p. 554). The robustness of findings across experimental studies and interventions suggests the need to address basic questions about the nature of gratitude. Are certain people - such as men or womenless inclined to experience gratitude and derive less benefit from gratitude? If there are gender differences in reactions to gratitude, what explains this effect?

Gratitude is associated with indebtedness and dependency among some people (Solomon, 1995). It is possible that men regard the experience and expression of gratitude as evidence of vulnerability and weakness, which may threaten their masculinity and social standing (Levant \& Kopecky, 1995). Consequently, men might adopt an avoidance orientation toward gratitude, showing a preference to conceal rather than express it. This would serve as a type of self-protective mechanism from contact with unwanted negative emotional experiences or adverse social consequences. Ironically, this avoidance orientation may cause even greater disruptions to psychological and social well-being. This orientation is expected to diverge from women who, on average, are more attuned to emotions and behaviors with the aim 
of creating and sustaining meaningful social relationships. Compared with men, women are expected to perceive gratitude as more functional or advantageous in their lives because of their heightened priority for creating and sustaining intimate relationships (Schwartz \& Rubel, 2005; Timmers, Fischer, \& Manstead, 1998). As a result, women are expected to derive greater benefits from the experience and expression of gratitude, including building strong and satisfying relationships.

People benefit from social relationships regardless of their social roles or value orientations (Argyle, 2001). Thus, if men tend to devalue and are less comfortable expressing gratitude, clinicians and researchers may need to give consideration to how these social cognitive processes potentially disrupt the operation of a potent source of well-being. Gratitude interventions may require refinements - being sensitive to gender and underlying processesso people find their own appeal in grateful behavior. The series of studies in this paper attempt to investigate gender differences in gratitude.

\section{Gender Differences in Emotions}

Women are generally more emotionally expressive than men and, with the exception of anger, experience emotions more intensely and frequently compared with men (Fujita, Diener, \& Sandvik, 1991; Grossman \& Wood, 1993; Kring \& Gordon, 1998; Naito, Wangwan, $\&$ Tani, 2005; Simon \& Nath, 2004). Women are more aware of their emotions and report more complex emotional experiences compared with men (Barrett, Lane, Sechrest, \& Schwartz, 2000; Ciarrochi, Hynes, \& Crittenden, 2005). On average, women also report a greater willingness to express their emotions openly and show stronger tendencies to regulate them to adapt to changing social circumstances compared with men (Timmers et al., 1998). Small to moderately sized differences between men and women in the experience and expression of emotions are contingent on multiple social, emotional, interpersonal, and contextual factors.

Differences in the experience and expression of positive emotions may amplify the benefits for women compared with men. Positive emotions feel good, serve the function of broadening people's mindsets, and allow for finite attentional resources to be redirected from unrewarding goals to other desired and more meaningful opportunities (Carver, 2003; Fredrickson, 1998). For example, positive emo- 
tions can aid human beings in their quest to satisfy the fundamental need to be accepted by other people (Baumeister \& Leary, 1995). Women tend to receive greater social support from peers compared with men (Eagley \& Crowley, 1986). One reason may be that women possess a greater tendency to recognize acts of goodwill by others, express their appreciation, and reinforce the likelihood these acts will be repeated. Upon encoding these shared positive experiences, a durable social resource is created, with both parties more likely to respond with variants of support and responsiveness when later faced with adversity. In other words, gratitude bolsters social bonds and friendships by building people's skills for caring, altruism, and acts of appreciation. Over time, gratitude - similar to other positive emotions - contributes to the growth of skills, relationships, and resilience. Thus, women might be at an advantage to experience psychological growth as a function of gratitude.

There are several plausible reasons why men seem less receptive to grateful feelings. Women and men are socialized differently and possess different values. In many cultures, women are expected to express certain emotions more frequently compared with men (Fischer, 1993; Grossman \& Wood, 1993; Kelly \& Hutson, 1999), and this expectation is more imperative for intense positive emotions (Stoppard \& Gruchy, 1993). Women are expected to engage in more caretaking roles. Women perceive social communication, interdependence, and the development, maintenance, and repair of relationships to be more important than do men. For example, one study of values across 70 countries found that men rated power, novelty and stimulation, hedonism, and achievement as their most valued priorities. In contrast, women's most important values were trying to understand and improve their relationships, be tolerant, and act in a benevolent manner toward other people (Schwartz \& Rubel, 2005). Due to deeply ingrained social norms or self-selected values, women focus greater efforts on regulating interpersonal relationships, whereas men focus their emotional expression on the maintenance and pursuit of power and status (Brody, 1997, 1999; Stoppard \& Gruchy, 1993).

Gender differences in social values and regulatory goals are important because the expression and sharing of positive emotions is strongly related with social adjustment (Ingoldsby, Horlacher, Schvaneveldt, \& Matthews, 2005). Gratitude is an other-focused emotion, and men may find gratitude to be less familiar and more 
discomforting compared with women. Moreover, with less practical experience and values that are inconsistent with the open expression of gratitude, men might find gratitude to be more challenging and anxiety provoking. If men are less oriented to the experience and expression of emotions, especially in social situations, then they are at a disadvantage for benefiting from gratitude. Men would be less likely to capitalize on how gratitude aids in the savoring of pleasant life experiences, validates social worth (i.e., gifts being objective evidence of acceptance by others), strengthens social bonds, and promotes prosocial behavior that creates opportunities for additional positive experiences.

Based on gender differences in values, whether or not men and women differ in emotional experience, expression, and benefits might depend on the situation in which gifts are recognized. For example, men are more likely to express emotions compared with women after achievement related events (Scherer, Wallbott, \& Summerfield, 1986). Yet gratitude often occurs in social situations in the absence of overt achievement. Thus, we expected the immediate and longerterm benefits derived from gratitude to be more pronounced for women compared with men.

There are a small number of published studies examining how gender influences gratitude. In one study, based on a country-wide essay assignment assessing gratitude in children, girls expressed more gratitude for social relationships, whereas boys felt more grateful for materialistic possessions (Gordon, Musher-Eizenman, Holub, \& Dalrymple, 2004). Furthermore, grateful feelings in social situations appear to be more frequently observed in young girls compared to boys (Baumgarten-Tramer, 1938). In a study of cross-cultural differences, older American men evaluated gratitude as less useful than other positive emotions such as love, enthusiasm, hope, compassion, and pride (Sommers \& Kosmitzki, 1988). A number of older American men (at least 35 years of age) reported an explicit preference for concealing rather than expressing gratitude. In contrast, none of the younger or older women in the study showed a preference for concealing gratitude. Two studies provide information on specific situational contexts where gratitude is influenced by gender. In one study, adult women were more likely than men to smile and say "thank you" when another person held the door open for them (Ventimiglia, 1982). In another study, older adult women were more likely to feel grateful to God compared with men (Krause, 2006). 
While providing bedrock, these studies failed to address the issue of why and how the experience and expression of gratitude might differ between men and women (for an exception, see Sommers \& Kosmitzki, 1988). Hence, research addressing potential mediators and moderators in explaining gender differences in gratitude are needed. We aimed to fill this void.

Gratitude is an attribution-dependent emotion (McCullough \& Tsang, 2004; Weiner, 1985). People experience gratitude when they value the benefit and think the benefactor intentionally bestowed the benefit or incurred some cost in providing it (Tesser, Gatewood, \& Driver, 1968). Therefore, studies designed to explain why men and women differ in the experience and expression of gratitude may prove fruitful if they assess grateful appraisals and attributions. In the current investigation, we measured people's appraisals of grateful experience and expression. Prior studies on gender differences in gratitude also failed to consider construct specificity or alternative models. In this study, we addressed this gap in the literature by examining whether gender differences in appraisals are specific to gratitude or are relevant to various intimate social behaviors. Examining gender as a moderator for gratitude compared to other social behaviors can provide evidence for or against the need to consider gender when investigating antecedents, consequents, and methods to enhance gratitude.

Appraisal patterns might explain why women might derive more benefits from gratitude compared with men. Appraisal theories suggest that emotions stem from how people evaluate objects, events, and possibilities. People's actions and emotional experiences are partially caused by their appraisals of potential costs and benefits, as well as an event's meaning (Lazarus, 1991). As opposed to what actually occurs, people experience different emotions in response to the same event because of variability in their appraisals. If appraisals influence what people feel and how they act, this model can provide insight into why men and women might experience different reactions to being beneficiaries. As noted earlier, social-cognitive processes including social norms and personal value priorities influence gender differences in emotional experiences. Based on this model, men were expected to be at a disadvantage in terms of experiencing and capitalizing on grateful emotions.

The work on gender differences in emotion suggests that men are less practiced at expressing emotions in the context of socializing. 
Men compared with women are proposed to be less willing to express softer, other-focused emotions such as gratitude. Bruch, Berko, and Haase (1998) found that emotional inexpressiveness mediated relations between a set of personality attributes (e.g., masculine ideology, shyness, physical attractiveness) and social competence. But masculine ideology (Study 2) - and not masculine identity (Study 1) - predicted emotional inexpressiveness. These data suggest that men high in masculine ideology (i.e., the degree to which a man agrees with traditional societal beliefs about masculinity) compared with men high in masculine identity (i.e., identifying with masculine characteristics and behaviors) are more likely to be emotionally inexpressive because masculine beliefs suggest that emotional expression is a sign of femininity and weakness (Pleck, 1981). Furthermore, men with greater masculine ideologies are more likely to be low in social competencies as a result of their emotional inexpressiveness. These processes may differ for older and younger adults.

Compared with younger adults, older adults tend to experience a shift in value priorities from accumulating experiences and knowledge to being more focused on the pursuit of living well in the fewer days remaining. They generally show more positive reactions to events than their younger counterparts. This is partially explained by their focus on the here and now (Carstensen, Isaacowitz, \& Charles, 1999) and emotionally meaningful relationships (Carstensen, Gross, \& Fung, 1997). The development of new relationships is eschewed in favor of spending time with established entities. Because existing relationships possess greater opportunities for more frequent reciprocal altruism and gratitude for these acts, older adults may be more prone to viewing gratitude as a positive, rewarding, essential experience compared with younger adults. However, there is one study suggesting that older men are less inclined to categorize gratitude as "positive" compared with other emotional states (Sommers \& Kosmitzki, 1988) due to thoughts and feelings of burden or obligation experienced after receiving a gift. Because men value power, novelty and stimulation, and achievement as more rewarding than intimacy, older men might be more likely to invest time and effort toward finding activities that increase the probability of positive experiences; intimate social exchanges and related emotions such as gratitude are likely to be less of a priority (Schwartz \& Rubel, 2005). Competing ideas about the role of age and gender in understanding gratitude require further empirical scrutiny. 


\section{Current Investigation}

In the last few years, researchers carefully designed studies and found strong empirical support for the potency of gratitude interventions. These successful findings suggest that gratitude is a promising, important element to address in clinical settings. Questions remain, however, as to whether important individual difference variables influence the degree to which gratitude is viewed positively, willing to be expressed (as opposed to avoided), and associated with psychological well-being.

We reviewed evidence suggesting that women report more intense emotional experiences, are more willing to express their emotions, and derive greater benefits from them compared with men. Based on this work and the small subset of studies on gender differences in gratitude, we expected women to experience and express greater gratitude and derive more benefits than men. Women might possess an advantage over men in deriving rewards from their gratitude experiences because of their increased awareness and acceptance of emotions; they are also likely to be more practiced in executing complex behavioral strategies to create, preserve, and enhance intimate relationships.

In this paper, we conducted three studies, using different methodologies, to better understand whether-and more importantly howgender influences the experience, expression, and benefits of gratitude. Study 1 examined how men and women appraise the expression of gratitude to benefactors. Men were expected to appraise the expression of gratitude as being more unfamiliar and challenging and less rewarding compared with women. Men also were expected to be more conflicted about whether to engage or escape from the act of expressing their feelings. As a test of construct specificity, we examined whether men differed from women in how they appraise another intimate social behavior: confiding in another person about something very important. Prior studies cannot rule out the alternative hypothesis that men and women differ in intimate social behavior-beyond gratitude. In Study 2, participants wrote about the most meaningful episode over the past week when they received a gift from someone else. Afterwards, they appraised the quality of their experience. This narrative approach reduced the social desirability bias of asking people to directly evaluate gratitude. In addition, we sought to explore how gender and age differences operate together in predicting responses to 
gratitude by sampling from college students and the community. To generalize our findings, we examined different appraisals in Studies 1 and 2. Also, we examined gender differences in gratitude dispositions in both Studies 2 and 3. As the primary focus of Study 3, we used a prospective design to test whether men and women differed in how gratitude influenced well-being over a 3-month period. According to self-determination theory (Deci \& Ryan, 1985), humans seek to satisfy basic needs such as feelings of relatedness to other people, autonomy, and competence. We operationalized well-being as changes in the satisfaction of these needs. As a final component, we tested the hypothesis that gratitude is associated with less well-being in men, compared with women, as a function of their preference for concealing rather than openly expressing their emotions.

\section{STUDY 1: APPRAISING THE EXPRESSION OF GRATITUDE}

Study 1 investigated gender differences in the evaluation of directly expressing gratitude to a gift giver. Much of the literature on gratitude has focused on the experience but not the expression of gratitude. One notable exception is a study showing that a number of older American men showed a preference for concealing rather than expressing gratitude (Sommers \& Kosmitzki, 1988). Expressing gratitude motivates kindness and other moral behaviors and, thus, is theorized to be an important process in creating positive social outcomes (McCullough, Kilpatrick, Emmons, \& Larson, 2001). Research has suggested that the ease and high rate of emotional expressiveness of women contributes to their ability to develop intimate relationships (Dindia \& Allen, 1992; Reis, 1998; Taylor et al., 2000). As such, we examined whether women evaluated the expression of gratitude as more rewarding and less novel and challenging compared with men. This was tested against an alternative model that there was nothing inherently unique about gratitude. Women might generally find intimate social activity that is not inherently about emotions (confiding in someone else) to be more enjoyable and less novel and challenging compared with men. Berlyne (1960) theorized that novel and challenging events can evoke approach or avoidance motivation. He discussed how the abstract qualities of novelty, complexity, uncertainty, and conflict determine the likelihood of particular motivation orientations. Using this framework, 
we had participants evaluate the expression of gratitude and other intimate social behaviors on several dimensions reflecting novelty/ challenge as well as potential reward value.

Gratitude was expected to be more challenging and possess less reward value for men. This is because of men's socialized belief systems about manhood. Receiving a gift could imply that another person was needed to obtain desired end states. Because these desired end states were satisfied with the aid of others, a person might evaluate themselves as weak and possessing less power than desired. Unwanted feelings of dependency might be primed. If a person believes there is an obligation to reciprocate the receipt of gifts, the pleasurable state of gratitude would be attenuated, intensifying the unpleasant feeling of burden. Based on men's tendency to value autonomy and power substantially more than women, they were expected to view gratitude as less rewarding and more challenging.

\section{Method}

\section{Participants}

Participants were 288 college students (mean age $=19.49, S D=3.26$ ) at a large, public, Mid-Atlantic university. There were 205 women $(71.2 \%)$ and 83 men (28.8\%). The majority were Caucasian (60.8\%), with the remaining participants defining themselves as Hispanic/Hispanic-American (13.2\%), Asian/Asian American (9.7\%), African American (7.6\%), Middle-Eastern $(3.1 \%)$, and Other $(5.6 \%)$.

\section{Procedure and Measures}

The research study was posted on an online forum for college students seeking research participation to meet requirements for undergraduate college courses. Participants completed an anonymous Web-based survey and, in return, received research credit.

After being asked to report demographic information, participants made appraisal ratings for seven hedonistic and seven personal-growth-oriented behaviors that they might engage in on a given day (Steger, Kashdan, \& Oishi, 2008). For this study, we focused on the two items reflecting intimate social behavior: expressed my gratitude (verbally or in writing) to someone who did something for me and confided in another person about something 
very important to me. Both of these behaviors involved expressing personally salient information in the context of an intimate social interaction. ${ }^{1}$

Participants were asked to think about what it would be like to express gratitude and confide in someone else. Each behavior was separately evaluated on six dimensions using the following 7-point semantic differential scales: (1) novelty - for me, engaging in this activity is common to novel; (2) complexity - for me, engaging in this activity is simple to complex; (3) uncertainty - thinking about this activity, it is easy to predict the outcome to difficult to predict the outcome; (4) conflict-for me, deciding whether to engage in this activity is not a conflict to a large conflict between the costs and benefits, (5) interestingness - for me, engaging in this activity is uninteresting to interesting; and (6) excitement - for me, engaging in this activity is boring to exciting.

\section{Results and Discussion}

To test hypothesized gender differences, we conducted a series of repeated measures ANOVAs with a focus on Gender $\times$ Behavior (expressing gratitude vs. confiding) on each of the six appraisal dimensions. Significant Gender $\times$ Behavior interactions were found for complexity, $F(1,278)=4.94, p=.03$, uncertainty, $F(1,281)=8.79$, $p=.003$, conflict, $F(1,283)=11.22, p=.001$, interestingness, $F(1$, $283)=3.92, p<.05$, and excitement, $F(1,280)=4.92, p=.03$; no interaction effect was found for novelty $(p=.28)$, but there was a main effect for gender $(p=.05)$ with women evaluating both intimate behaviors as less novel compared with men. Upon interpreting these interaction effects, women evaluated the expression of gratitude to be less complex, uncertain, and conflicting and more interesting and exciting compared with men. There were no significant gender differences on the appraisals for confiding in other people. Descriptive data are shown in Table 1. Evidence showing that women evaluate the expression of gratitude as less difficult and challenging, less confusion about

1. All seven of the hedonistic behaviors are not directly relevant to the topic of gratitude: had sex purely to get pleasure; bought a new piece of jewelry or electronics equipment just for myself; got drunk; got high on drugs; kept eating more than I intended of something just because it tasted so good; masturbated; and went to a big party. The other five behaviors were not directly relevant to our interest in evaluating situations where another person can be providing benefits. These five behaviors were intrapersonal (wrote out my goals for the future; persevered at a valued goal even in the face of obstacles), involved being generous (gave money to a person in need; listened carefully to another's point of view; volunteered my time). 


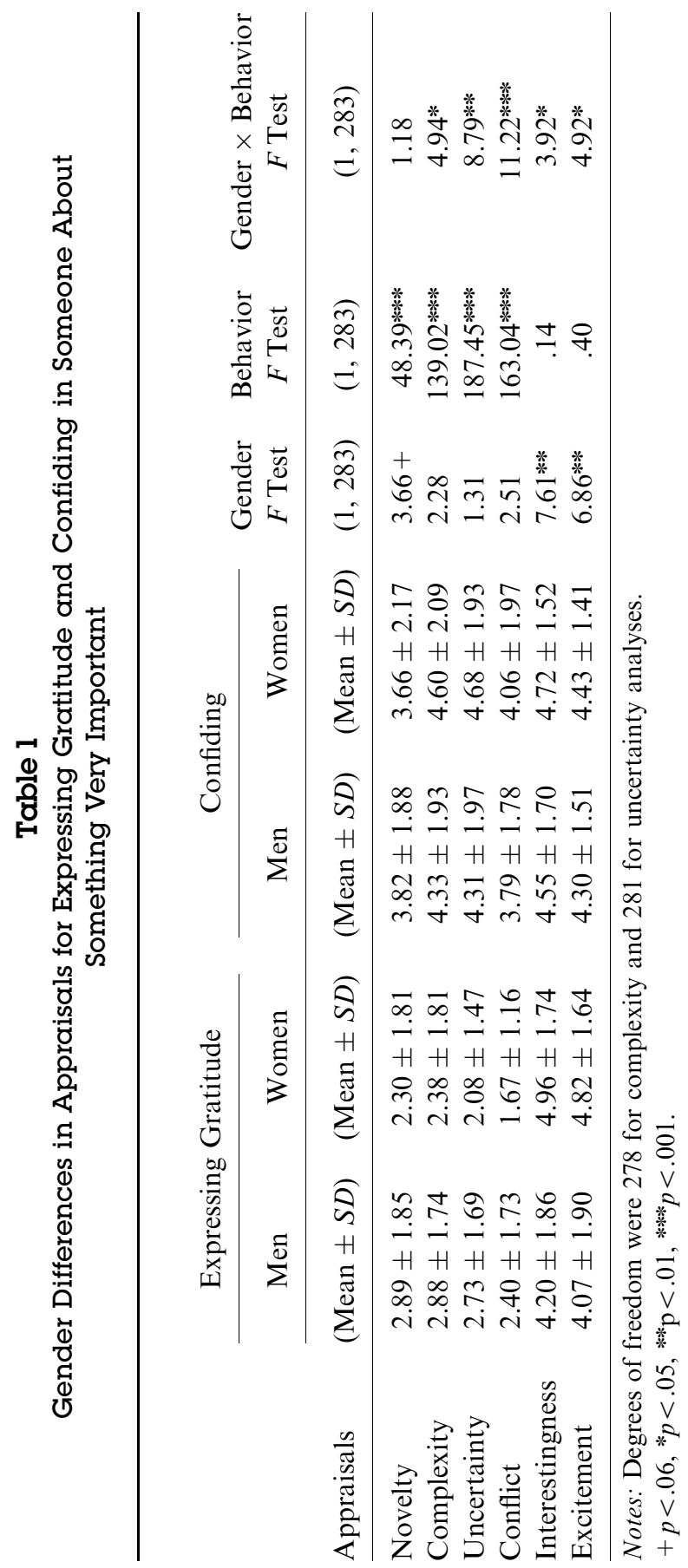


whether to approach or avoid (internal conflict), and greater interest and excitement were not found for a different variant of intimate social behavior. These data suggest there is something unique about gratitude. It is viewed as more beneficial and less costly for women compared with men.

Findings from Study 1 provide support for the prediction that women and men value the expression of gratitude differently. Because the expression of gratitude serves as a moral motivator, these gender differences might translate into the stronger social bonds, larger social networks, and greater kindness, empathy, and helpseeking behavior seen in women compared with men (Fehr, 1996; Reis, 1998). An important feature of Study 1 was the comparison between how the sexes differed in their appraisals of expressing gratitude compared with other intimate social behavior. This allowed us to test the construct specificity of our findings. The evidence showed that gender differences in social behaviors may be more fine-grained than previously imagined and that the elements of gratitude are valued differently between men and women. Men's tendency to evaluate the expression of gratitude as novel and uncertain may reflect their lack of experience, their self-efficacy in executing the behavior, internal conflicts about perceived costs and benefits, or some combination of these and other factors. One of the strengths of this study was the breadth of appraisals and their linkage to prior research on approach-avoidance frameworks. Most of Berlyne's work has been neglected despite offering great potential to understand how people react and behave in their everyday environment.

Although Study 1 provided data consistent with gender differences in appraisals of expressing gratitude, it is important to identify some design limitations. Gratitude is a simple construct for people to grasp, and other researchers have found success measuring it with one- and two-item scales (McCullough, Tsang, \& Emmons, 2004). A single item to assess the expression of gratitude, however, limits our ability to generalize to the various reactions people can have to receiving gifts in everyday life. A related measurement issue was our failure to explicitly assess appraisals relating to positive and negative feelings, obligation and burden, and prosocial motivation. Additionally, findings were circumscribed to college students when at least one study posits age differences in attitudes toward gratitude (Sommers, 1984). Study 2 addresses these measurement issues by 
using a life narrative approach and an entirely different set of appraisals in college students and older adults in the community.

\section{STUDY 2: APPRAISALS FOR GRATITUDE LIFE NARRATIVES}

As a methodological improvement, in this study, participants wrote a detailed personal narrative about the most meaningful time over the past week when they received a gift from another person. After writing narratives, participants appraised their event on the intensity of felt gratitude, general positive and negative feelings, feelings of burden and obligation, and motivation to engage in moral behavior toward other people following the event. This idiographic approach allowed for a real-world assessment of how people evaluate the experience and expression of gratitude. Research on gender differences in value priorities and the importance that men place on being autonomous as opposed to dependent suggests that they might evaluate the gratitude process as possessing less reward potential and greater burden and obligation compared with women. In addition to narratives, we also examined gender differences on a traditional selfreport measure of trait gratitude.

Most of what is known about the experience, expression, and appraisals of positive emotions has been based on work with college students. As a result, our understanding of positive emotions among older adults and across the life span is relatively limited. To address the potential boundary conditions of gender differences in gratitude, in this study, we examined whether gender differences in the experience, expression, and appraisals of gratitude differed across older adults and college students. This is an extension of the only published study we are aware of on age and gender on gratitude (Sommers, 1984). Carstensen and her colleagues provide evidence that as people get older, value priorities and goals shift from knowledge seeking and achievement to investing in events that provide emotional meaning (Carstensen et al., 1999; Charles \& Carstensen, 2007). This is proposed to be a result of recognizing how much time in life is left and the need to focus on consistent sources of meaning and pleasure. Exploring new avenues potentially conflicts with this goal because of the higher uncertainty of finding meaning or pleasure and greater anxious feelings associated with being uncertain. Based on this model, older adults were expected to interact more regularly 
with close, intimate people in their lives where gift giving and gratitude are more likely compared with strangers and acquaintances. By selecting particularly fertile environments for creating and extracting meaning, older adults might be in a position to experience greater rewards and less punishment from grateful feelings and their behavioral expression.

Based on prior work, we expected age and gender effects when asking people to evaluate life narratives when they received a gift. Women (compared with men) and older adults (compared with younger adults) were expected to report more intense gratitude and judge the experience to be more rewarding, less unpleasant and burdensome, and provoking greater motivation to do good for someone else. On a more exploratory basis, we examined potential gender and age differences in the types of benefactors recalled in salient life narratives, types of gifts received, and whether the type of benefactor and gift affects subsequent responses to being the beneficiary of others' goodwill.

\section{Method}

\section{Participants}

Seventy-seven older adults (mean age $=69.58$, range $=59-85, S D=6.39$ ) participated. Participants were recruited from the Osher Lifelong Learning Institute (OLLI) at George Mason University. The OLLI is a nonprofit organization focused on the continuing education, socializing, and intellectual stimulation of retired older adults in the community. Our sample included 47 women $(61.8 \%)$ and 29 men $(38.2 \%)$, the majority being Caucasian (98.7\%). In addition, we recruited 214 college students (mean age $=20.52$, range $=18-48, S D=4.06$ ) from a large, public, Mid-Atlantic university. The sample included 155 women $(72.4 \%)$ and 59 men $(27.6 \%)$. The majority were Caucasian (55.4\%), with the remaining participants defining themselves as Asian/Asian American (18.8\%), Hispanic/Hispanic American (8.5\%), African American (8.5\%), Middle-Eastern $(4.7 \%)$, Mixed or Other $(2.8 \%)$, and $1.4 \%$ provided no response.

\section{Procedure}

We recruited older adult volunteers by advertising in the OLLI e-newsletter and flyers. Interested older adults were asked to contact the experimenter via e-mail or phone. Upon being contacted, a paper-and-pencil survey was delivered to them. Older adults did not receive compensation. We recruited college students from the undergraduate psychology subject pool at a large, public, Mid-Atlantic university. Students scheduled an 
appointment at our laboratory. Upon arrival, participants completed a paper-and-pencil survey. Students received course credit for participation.

\section{Measures}

Both samples received identical paper-and-pencil surveys that included all the measures described for this study. This included items addressing basic demographic information including age, gender, romantic relationship status, socioeconomic status, and race/ethnicity.

Trait gratitude. The six-item Gratitude Questionnaire-6 (GQ-6; McCullough et al., 2002) was used to assess the general frequency, intensity, density, and span of gratitude in people's lives $(\alpha=.94)$. Example items include "If I had to list everything that I felt grateful for, it would be a very long list" and "Long amounts of time can go by before I feel grateful to something or someone" (reverse-scored). Responses are provided using a 5-point Likert scale rated from 1 (strongly disagree) to 7 (strongly agree). The GQ-6 has been shown to exhibit excellent psychometric properties, and relations with psychological, physical, and social well-being cannot be accounted for by higher-order personality traits (i.e., Big Five) and social desirability (McCullough et al., 2002, 2004).

Appraisals of gratitude life narratives. Participants were asked to provide a narrative of their most personally meaningful experience of gratitude in the last 7 days. They were told to leave it blank if they did not experience any gratitude over the past week. However, each of the participants reported that they received at least one gift during the past week and were able to write about it. Two examples of narratives reflecting the range of gifts received follow:

I work as a waitress and normally receive $10 \%-20 \%$ tips from my customers. Two days ago, though, I received over $50 \%$, which was a $\$ 20$ tip on a $\$ 40$ meal!

A friend died this past week ... it was a shock. I decided to go to my sing-along class as usual later that day, and felt an enormous well of support from my community of friends.

Upon completing their narratives, participants were asked several questions about their gratitude experience using 7-point Likert scales from 1 (not at all/very little) to 7 (extremely). Participants provided several ratings, including the intensity of the emotion, the degree to which the experience was pleasant or unpleasant or both, their sense of burden, and 
whether or not they felt it was important to help or do something good for other people after the experience (e.g., prosocial motivation). Thus, participants completed five independent appraisals about their narrative.

Besides the five appraisals, participants were asked to describe their relationship with the benefactor using the following response options: romantic partner, parent, friend, child or children, close relative or other family member, stranger, God, destiny or luck, or nature.

Narratives were coded by trained raters to determine if gifts were best classified as tangible (i.e., material gift) or intangible (e.g., social support, time). Raters also coded the gender of benefactors. However, this was not always possible because gender is not relevant to certain benefactors such as parents or God, and often, not enough information was available. Rater training required approximately $15 \mathrm{hr}$ of discussions on assigned gratitude and life narrative readings and instruction in evaluating protocols from other studies. Meetings were held after every three participants to prevent behavioral drift. For analyses, we used data based on consensual agreements made between raters. Two raters coded all available narratives for reliability purposes. Using Cohen's kappa coefficient, interrater reliability was excellent for ratings of tangible or intangible gifts $(\kappa=.86)$ and type of benefactor $(\kappa=.84)$.

\section{Results and Discussion}

Initial analyses focused on trait gratitude or the GQ-6. There was evidence for gender differences with women $(M=36.40, S D=4.62)$ endorsing greater trait gratitude compared with men $(M=34.67$, $S D=6.29), t(288)=2.62, p<.01$. Upon examining the word count of narratives, we failed to find significant differences in length between college student women $(M=45.07, S D=35.83)$ and men $(M=46.67, S D=28.64)$. However, older women $(M=54.25$, $S D=46.45)$ wrote longer narratives compared to older men $(M=34.54, S D=24.19), t(66)=1.94, p=.06$.

As for participant descriptions of benefactors, $30.2 \%$ were parents, $23.6 \%$ friends, $22.2 \%$ romantic partners, $11.5 \%$ close family, $5.3 \%$ God, $3.6 \%$ strangers, $2.2 \%$ destiny/luck, and $1.3 \%$ nature. Coding gender of benefactors revealed that $34.1 \%$ were women, $25 \%$ men, $2.4 \%$ spiritual beings, $23.8 \%$ fit in an "other" category (e.g., parents, teammates), and $14.7 \%$ did not include enough information to be coded. When coding gifts, $67.6 \%$ were defined as being intangible and $32.4 \%$ as tangible.

Using chi-square analyses, we examined gender and age differences on gift type (tangible vs. intangible), benefactor gender, and 
relationship between participant and benefactor. We did not find significant gender or age effects on tangible or intangible gifts $(p s>.30)$. For older adults, there were no significant gender differences in the gender or reported relationships with benefactors ( $p s \geq .40$ ). For younger adults, we found significant differences in the gender of benefactors, $\chi^{2}(4,184)=13.73, p=.008$. For men, $50 \%$ of benefactors were women and $18 \%$ men $(32 \%$ could not be classified by gender, e.g., parents, community); for women, $29.1 \%$ of benefactors were women, $35.8 \%$ men, and $3 \%$ God $(22 \%$ could not be classified by gender). For younger adults, we also found significant differences in relationships with benefactors, $\chi^{2}(9,171)=16.44$, $p=.06$. For men, $17 \%$ of benefactors were romantic partners, $42.5 \%$ parents, $27.7 \%$ friends, $6.3 \%$ close family members, $2.1 \%$ strangers, and $6.4 \%$ destiny or luck; for women, $25 \%$ were romantic partners, $37.9 \%$ parents, $21 \%$ friends, $6.5 \%$ close family members, $2.4 \%$ strangers, and $7.3 \%$ reported God or Nature. Thus, for younger adult women, the gift givers in narratives were more evenly balanced between men and women, suggesting they are more comfortable receiving gifts from a wide span of people. Men, on the other hand, had benefactors that tended to be women and designated as romantic partners, suggesting less flexibility in who they are comfortable with as gift providers.

To test hypothesized gender differences on the five appraisals relating to life narratives, we conducted a multivariate analysis of variance (MANOVA) with gender, age, and Gender $\times$ Age interaction effects. Because gender of benefactors was relevant, this variable was included in analyses. We conducted appropriate follow-up univariate tests to determine the nature of significant results.

A one-way MANOVA revealed a significant gender main effect, $F(5,250)=3.30, p<.01$, and a nearly significant age main effect, $F(5$, $250)=2.16, p=.06$, on gratitude appraisals; there was no support for a Gender $\times$ Age interaction. For gender effects, women reported more intense gratitude for the gift received, more pleasant feelings, and less burden and obligation compared with men. In terms of age effects, older adults reported less negative feelings and burden compared with younger adults. Descriptive data and results of univariate tests are shown in Table 2.

We also found an omnibus three-way Gender $\times$ Age $\times$ Gender of Benefactor interaction on gratitude appraisals $(p=.04)$. Upon examining univariate tests, the only significant effects were for pleasant 
feelings, $F(3,250)=2.91, p=.04$, and negative feelings, $F(3$, $246)=3.00, p=.03$; there were no significant main or two-way effects. The nature of these effects demonstrated that older men reported less pleasant feelings than everyone else when their benefactor was male $(X=5.0, S E=.79$; all other group means $>6.1)$. As for negative feelings, the findings could not be interpreted because the effects were for benefactors in the "other" category (instead of men or women). This result was not a primary aim and we do not discuss it further.

Study 2 found that younger and older women reported greater tendencies to feel grateful based on scores on a well-validated measure of trait gratitude. This study also moved beyond responses to predesigned gratitude questions to examine how men and women differ in their thoughts about a real-world episode when they were a gift recipient during the past week. Asked how they felt in response to the episode, women reported feeling greater gratitude and pleasantness and less burden and obligation compared with men. As evidence of construct specificity, the findings for general pleasant feelings for being a gift recipient diverged from gratitude reactions. Older and younger women and younger men all reported similar elevated pleasant feelings when receiving gifts. In contrast, older men reported less pleasure as a gift recipient. However, this Gender $\times$ Age interaction on pleasure was moderated by the gender of benefactors. Specifically, older men experienced substantially less pleasure when they received a gift from another man as opposed to from a woman. This may be something unique to the older cohort under study or may provide preliminary insight into the qualitative differences of how older men respond to tangible gifts, support, and aid from other men. There is the potential to feel dampened pleasure as a result of primed thoughts about power and status differentials compared to other men.

Gender differences in the emotional experience of gratitude might be related to different social-emotional skills for women compared with men and varied social consequences. For example, women tend to be more aware of their emotions and how to use them intelligently to obtain desired outcomes (Barrett et al., 2000). Greater gratitude experiences and more positive and less negative reactions reinforce the willingness to openly express future gratitude experiences. Relative to women, men exhibited a slight deprivation in this valuable source of intrapersonal and interpersonal benefits.

This study contributed to a better understanding of gender differences in gratitude by focusing on benefit and cost appraisals associated 


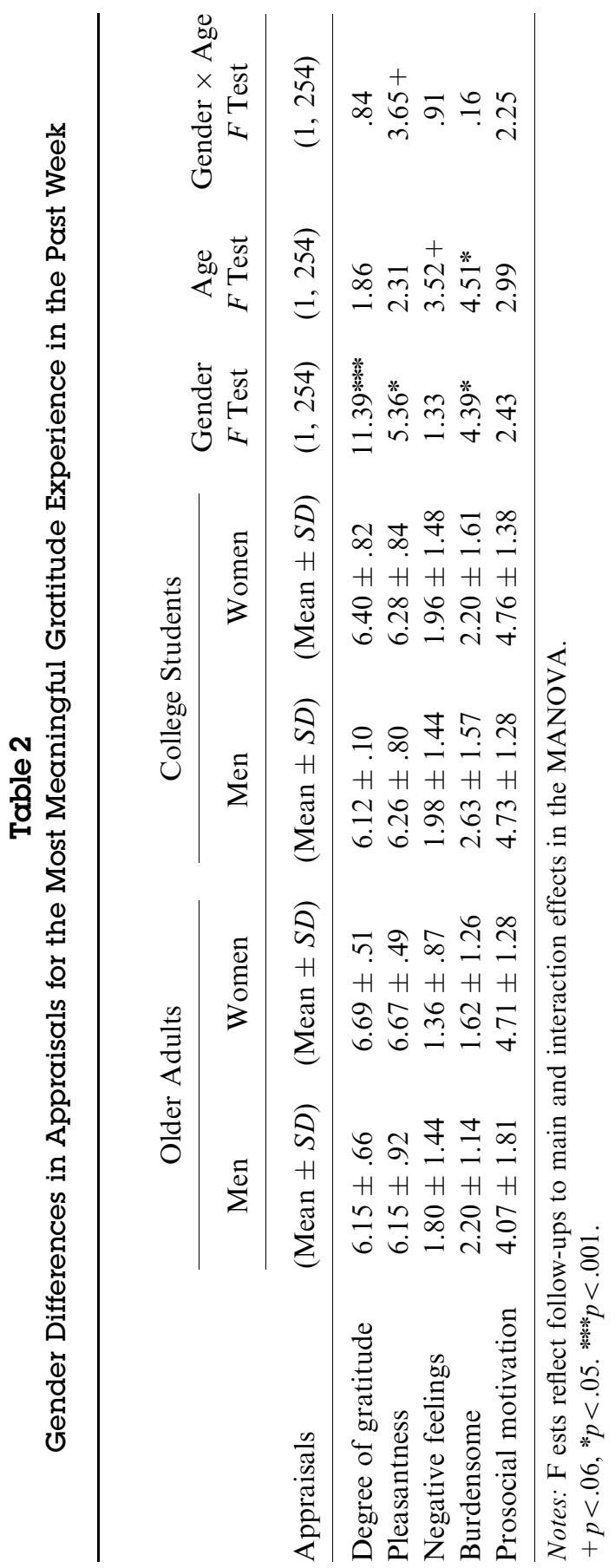


with receiving gifts from others. Instead of relying on responses to global self-report questionnaires, the methodology offered novel insights into the understanding of gratitude by using real-life narratives (McAdams, 2001). Women generally reported greater gratitude and found it to be more advantageous than men. In addition, we found some evidence for gender differences in the types of benefactors characterized by the most salient gratitude episode in people's lives during a limited time period. Women are more likely to report episodes with romantic partners or God as gift giver, and men were more likely to report episodes with friends or destiny/luck as gift giver. These findings parallel dominant gender roles, with women possibly being more likely to receive gifts from men or men being less likely to recognize or appreciate these gifts compared with attention given to cultivating close friendships. However, these interpretations should be considered speculative until further work accounts for within-person variability in gift giving and receiving in various social relationship contexts.

Carstensen's work shows that older adults tend to show stronger positive reactions to events than younger adults. Part of this stems from a value shift from accumulating experiences and knowledge to being attuned to extracting meaning and pleasure from known sources. We found that older adults derived fewer rewards when they were the recipient of another man's generosity, which may produce a conflict between the rewards of the gift itself and the internal struggle to feel empowered and high in status; importantly, older men were no different than anyone else in terms of reaping the rewards when women provided them gifts. We also found that older adults generally showed less negative affective and cognitive reactions to being a gift recipient.

Based on results from Studies 1 and 2 and relevant theory, there is no reason to expect the mechanisms explaining gender differences in gratitude to differ for older and younger adults. Expressing gratitude is an index of being interconnected to other people, and the social norms for men emphasize power and autonomy as opposed to reliance and dependence on other people. Receiving a gift might elicit conflict between positive feelings and the importance of being autonomous. Men may be less willing to express emotions because it might cause them to appear vulnerable and affect their goal to be autonomous. We tested this model in the next study. 


\section{STUDY 3: GENDER DIFFERENCES IN THE PROSPECTIVE BENEFITS OF GRATITUDE}

Whereas Studies 1 and 2 primarily focused on gratitude behaviors and episodes, Study 3 focused on grateful dispositions. As a replication of Study 2, we began by examining whether men and women differed in their possession of grateful dispositions. The primary aim of Study 3, however, was to examine potential gender differences in the benefits associated with grateful dispositions. To meet this aim, we used a prospective design and examined whether men and women differed in how gratitude leads to well-being during a 3-month period. Building on our interpretation of Study 2 findings, we operationalized well-being as the satisfaction of needs for relating to other people and being autonomous; less relevant was the need to feel competent - the final dimension of well-being defined by self-determination theory (Deci \& Ryan, 1985). Finally, we tested a plausible mechanism for potential gender differences in how gratitude relates to changes in well-being over time. It was hypothesized that gratitude would be associated with less well-being in men, compared with women, as a function of their predisposition to alter, control, or conceal emotions as opposed to openly expressing them.

\section{Method}

\section{Participants}

One hundred ninety undergraduate college students (mean age $=23.03$, $S D=5.90)$ at a large, public, Mid-Atlantic university participated. At Time 2 (T2), 153 individuals from $\mathrm{T} 1$ completed a 3 -month follow-up assessment ( $80 \%$ retention rate). The T2 sample included 118 women $(77.1 \%)$ and 35 men $(22.9 \%)$. The majority of the sample was Caucasian (66.7\%), with remaining participants defining themselves as Asian/Asian American (9.3\%), Hispanic/Hispanic American $(3.9 \%)$, African/African American $(3.9 \%)$, and Mixed or Other $(11.6 \%)$, and 7 participants failed to provide data.

\section{Procedure}

Participants completed an anonymous Internet-based survey. At T1, all participants completed several predictor and outcome questionnaires (see Measures) and gave consent to be contacted for future studies. Three months later, at $\mathrm{T} 2$, participants were emailed a Web link to access the follow-up survey. The T2 survey was comprised of the same predictor and 
outcome questionnaires found in the T1 survey. Students received research credit for their participation and were required to complete the initial survey and 3-month follow-up survey to receive full course credit.

\section{Measures}

Trait gratitude. The 6-item Gratitude Questionnaire-6 (GQ-6; McCullough et al., 2002) was used to assess the general frequency, intensity, density, and span of gratitude in people's lives $(\alpha=.93)$.

Trait global affect. The 20-item trait version of the Positive and Negative Affect Schedule (PANAS; Watson, Clark, \& Tellegen, 1988) assesses two distinct dimensions of general emotions. The 10-item Positive Affect subscale $(\alpha=.85)$ assesses activated positive emotions (e.g., excited, joy) and the 10-item Negative Affect subscale $(\alpha=.96)$ assesses activated negative emotions (e.g., anxious, jittery). Responses are provided using a 5-point Likert scale and participants are asked how they generally feel, rated from 1 (very slightly) to 5 (extremely). The PANAS has demonstrated consistent independence between the two affect subscales as well as excellent psychometric properties (Watson, 2000).

Psychological well-being. The 21-item Basic Psychological Needs Scale (Gagné, 2003) was used to assess Relatedness (eight items; $\alpha=.90$ ), feeling that satisfying and meaningful connections are being made with others, Autonomy (seven items; $\alpha=.81$ ), feeling that one's choices and activities are self-determined as opposed to being controlled by internal or external pressures, and Competence (six items; $\alpha=.86$ ), feeling a sense of mastery in one's activities. Responses are provided using a 7-point Likert scale rated from 1 (not at all true) to 7 (very true). This scale has good psychometric properties and has been shown to be predictive of prosocial behaviors (Gagné, 2003). This scale is part of a "family of scales," and the work version of the basic needs scale has been used most often. Research has shown that fulfilling these needs predicts greater job satisfaction, motivation, and productivity (Deci, Guardia, Moller, Scheiner, \& Ryan, 2006; Ilardi, Leone, Kasser, \& Ryan, 1993). Fulfilling these needs in relationships predicts attachment security and well-being (La Guardia, Ryan, Couchman, \& Deci, 2000).

Positive emotion expressiveness. The 16-item Berkeley Expressivity Questionnaire (BEQ; Gross \& John, 1995) assesses individual differences in the acceptance and willingness to overtly express emotions. The BEQ consists of three subscales with the current study focused on tendencies to express 
positive emotions (e.g., "When I feel positive emotions, people can see exactly what I am feeling"; $\alpha=.74$ ). Responses are provided using a 7-point Likert scale rated from 1 (strongly disagree) to 7 (strongly agree). The BEQ appears to demonstrate strong psychometric properties, with a 2-month test-retest reliability of .86 (Gross \& John, 1995). As evidence of convergent and discriminant validity, self- and peer ratings of positive emotional expression predicted the behavioral expression of positive emotions, but not negative emotions, in the laboratory (Gross \& John, 1997, 1998).

\section{Results}

Preliminary Analyses

Means and standard deviations for scales at $\mathrm{T} 1$ and $\mathrm{T} 2$ are reported in Table 3. Bivariate correlations are also reported. There was evidence for gender differences on the GQ-6 with women $(M=36.80$, $S D=5.39$ ) endorsing a greater frequency, intensity, density, and span of gratitude in their lives compared with men $(M=34.83$, $S D=5.52), t(142)=1.87, p=.06$. As for well-being, women reported greater satisfaction of their need to belong or relatedness compared with men, $t(141)=1.92, p=.05$, but there were no gender differences on autonomy or competence $(p \mathrm{~s}>.50)$.

\section{Primary Analyses}

Gratitude and gender as predictors of changes in well-being. We constructed three separate hierarchical regression models to examine whether gender moderated the effects of T1 gratitude (GQ-6) on psychological well-being. T2 relatedness, autonomy, and competence (Basic Psychological Needs subscales) served as dependent variables. At Step 1, T1 baseline scores were entered to create residual change scores in relatedness, autonomy, or competence from T1 to T2. At Step 2, T1 positive and negative affect (PANAS subscales) were entered as covariates. At Step 3, T1 main effects for gender and gratitude were entered. Finally, at Step 4, the T1 Gender $\times$ T1 Gratitude interaction was entered. In addition, to examine construct specificity, Gender $\times$ T1 Positive Affect and Gender $\times$ T1 Negative Affect interactions were also entered at Step 3. Continuous predictor variables were centered and significant interaction effects were explored with simple effect analyses (Aiken \& West, 1991). Gender was dummy coded with women coded as 0 and men as 1 . 
As predicted, we found support for gender as a moderator of gratitude effects on changes in well-being over time. After the full model was run, we removed the nonsignificant Gender $\times$ T1 Positive Affect and Gender $\times \mathrm{T} 1$ Negative Affect interactions ( $p$ s ranged from .18 to .60), and a reduced model was tested (see next section for more detail). The two-way interactions between gender and gratitude remained significant in these reduced models for relatedness, $F \Delta(1$, $136)=4.39, R^{2} \Delta=.02, p=.04$, and autonomy, $F \Delta(1,136)=4.48$, $R^{2} \Delta=.02, p=.04$, as shown in Table 4 . For women (over and above main effects, $R^{2}=.53$ ), gratitude was positively related to greater relatedness over time, $t(105)=2.43, R^{2} \Delta=.03, p=.02$, whereas for men (over and above main effects, $R^{2}=.43$ ), gratitude was not significantly related to relatedness $\left(R^{2} \Delta=.00, p=.64\right)$. In addition, for women (over and above main effects, $R^{2}=.42$ ), gratitude was positively related to greater autonomy over time, $t(105)=2.15$, $R^{2} \Delta=.02, p=.03$, whereas for men (over and above main effects, $R^{2}=.31$ ), gratitude was not significantly related to autonomy $\left(R^{2} \Delta=.02, p=.35\right)$. Gratitude did not significantly predict changes in competence.

Specificity of gratitude effects. The specificity of gratitude effects was examined by including trait positive and negative affect in the initial models as main and interaction effects. As shown in Table 4, gratitude effects remained even after controlling for significant variance attributable to positive affect. In addition, Gender $\times$ Positive Affect and Gender $\times$ Negative Affect interaction effects on changes in relatedness and autonomy failed to reach statistical significance in predicting relatedness $(p s=.49$ and .18$)$ or autonomy $(p s=.60$ and .40) and were subsequently dropped from the initial model. Conservatively controlling for these additional interaction effects had almost no influence on the Gender $\times$ Gratitude interaction on changes in relatedness $(p=.02)$ or autonomy $(p=.08)$. Taken together, these data support the construct specificity of our findings.

Reverse causation model. Bidirectional relations could be hypothesized such that relatedness or autonomy and relevant interactions with gender predicted changes in gratitude. We found no support, however, for these main ( $p s>.65)$ or interaction $(p s>.15)$ effects in predicting changes in gratitude. 


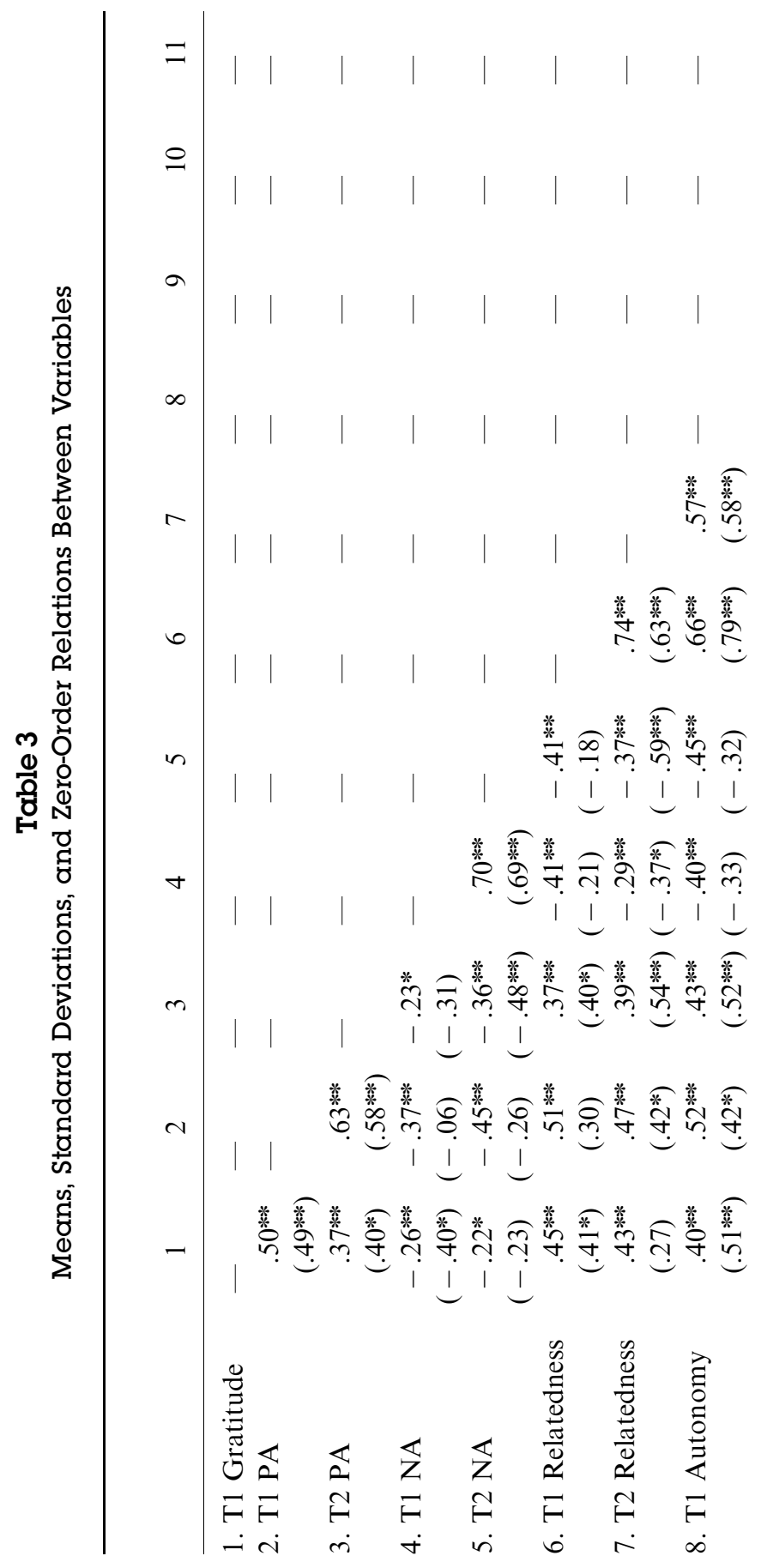




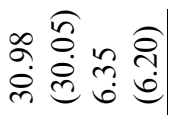

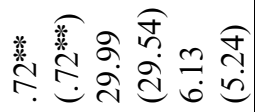

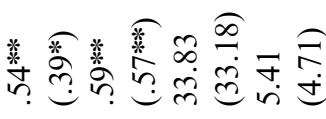

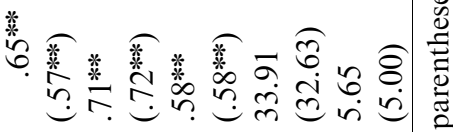

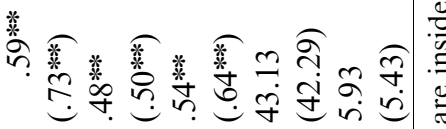

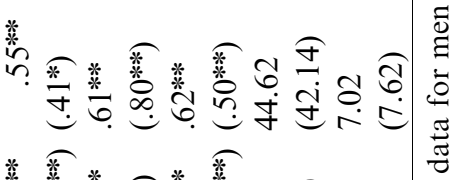

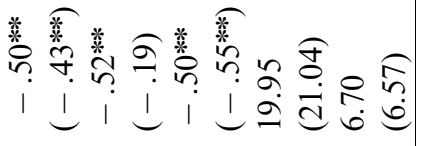

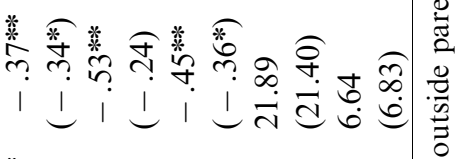

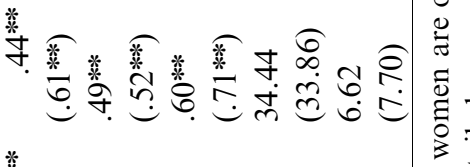

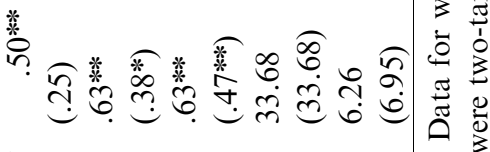

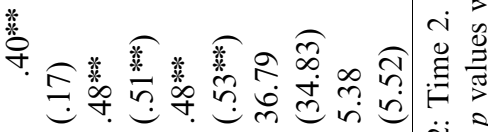

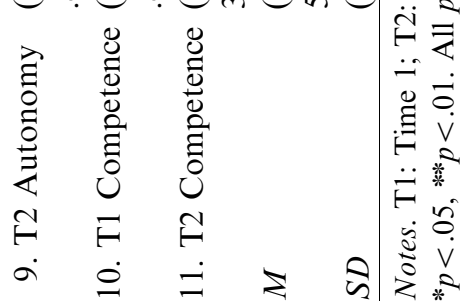




\section{Table 4}

Hierarchical Regression Models of Gratitude Predicting Changes in Psychological Well-Being With Gender as Moderator

\begin{tabular}{|c|c|c|c|c|c|c|c|}
\hline Step & & $B$ & $S E_{b}$ & $p r$ & $T$ & $\Delta R^{2}$ & $\Delta F$ \\
\hline \multicolumn{8}{|c|}{ Dependent variable: relatedness } \\
\hline 1 & T1 Relatedness & .63 & .07 & .62 & $9.21 * * * *$ & .51 & $145.91 * * * *$ \\
\hline \multirow[t]{2}{*}{2} & T1 Positive Affect & .16 & .06 & .22 & $2.65^{* * *}$ & .03 & $5.18^{* *}$ \\
\hline & T1 Negative Affect & -.03 & .06 & -.04 & -.44 & & \\
\hline \multirow[t]{2}{*}{3} & T1 Gratitude & .11 & .07 & .12 & 1.41 & .00 & .44 \\
\hline & Gender & .10 & .13 & .03 & .40 & & \\
\hline 4 & Gratitude $\times$ Gender & -.26 & .13 & -.18 & $-2.10^{*}$ & .02 & $4.39 *$ \\
\hline \multicolumn{8}{|c|}{ Dependent variable: autonomy } \\
\hline 1 & T1 Autonomy & .47 & .07 & .49 & $6.49^{* * * *}$ & .40 & $95.15^{* * * *}$ \\
\hline \multirow[t]{2}{*}{2} & T1 Positive Affect & .13 & .07 & .15 & 1.77 & .04 & $4.29 *$ \\
\hline & T1 Negative Affect & -.13 & .07 & -.16 & -1.92 & & \\
\hline \multirow[t]{2}{*}{3} & T1 Gratitude & .11 & .08 & .11 & 1.30 & .00 & .10 \\
\hline & Gender & -.06 & .14 & -.04 & -.41 & & \\
\hline 4 & Gratitude $\times$ Gender & -.30 & .14 & -.18 & $-2.12 *$ & .02 & $4.48 *$ \\
\hline \multicolumn{8}{|c|}{ Dependent variable: competence } \\
\hline 1 & T1 Competence & .53 & .08 & .48 & $6.39 * * * *$ & .51 & $148.02 * * * *$ \\
\hline \multirow[t]{2}{*}{2} & T1 Positive Affect & .22 & .07 & .25 & $3.02 * *$ & .05 & $8.64^{* * * * *}$ \\
\hline & T1 Negative Affect & -.11 & .07 & -.14 & -1.62 & & \\
\hline \multirow[t]{2}{*}{3} & T1 Gratitude & .13 & .08 & .13 & 1.57 & .01 & 1.99 \\
\hline & Gender & -.07 & .14 & -.04 & -.52 & & \\
\hline 4 & Gratitude $\times$ Gender & .01 & .14 & .01 & .09 & .00 & .01 \\
\hline
\end{tabular}

Notes: $N=143$.

$* p<.05,{ }^{* * *} p<.01,{ }^{* * *} p<.001$. All $p$ values were two-tailed.

Positive emotion expressiveness as a mediating mechanism. Linear regression analyses were computed to examine whether the Gender $\times$ Gratitude interaction on changes in the satisfaction of relatedness and autonomy were mediated by tendencies to accept and willingly express positive emotions. Following the guidelines of Baron and Kenny (1986), we examined whether the requisite conditions of mediation were met. Depicted in Figures 1 and 2 are each component of these mediation results for changes in relatedness and autonomy, respectively. The first condition, requiring the Gender $\times$ Gratitude interaction (independent variable) to be associated with well-being 


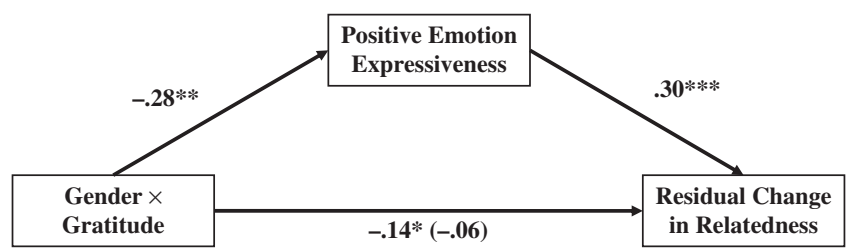

Figure 1

Positive emotional expressiveness as a partial mediator of the Gender $\times$ Gratitude interaction on residual changes in relatedness over a 3-month period. All coefficients are standardized estimates. The criterion variable reflects change in relatedness over the course of the 3 months under study. The beta coefficient in parentheses reflects the effects of Gender $\times$ Gratitude on changes in relatedness controlling for positive emotion expressiveness. $* * p<.01,{ }^{*} * * * 0.001$.

outcomes (dependent variables) was supported by prior analyses. The second condition, requiring the Gender $\times$ Gratitude interaction (independent variable) to be associated with positive emotion expressiveness (mediator), was supported for relatedness, $F \Delta(1$, $133)=9.99, R^{2} \Delta=.06, p=.002$, and autonomy, $F \Delta(1,133)=9.14$, $R^{2} \Delta=.05, p<.01$ (over and above $21 \%$ of variance attributed to main effects and covariates in each respective model). Upon decomposing this interaction, for women, gratitude was associated with greater emotion expressiveness, $t(100)=2.16, p=.03$, whereas for men, gratitude was associated with less emotion expressiveness, $t(30)=-2.19, p=.04 .^{2}$ The third condition was supported by evidence of significant associations between positive emotion expressiveness and changes in relatedness, $F \Delta(1,137)=27.06, R^{2} \Delta=.08$, $p<.001$ (over and above $53 \%$ for T1 relatedness), and autonomy, $F \Delta(1,137)=15.65, R^{2} \Delta=.06, p<.001$ (over and above $40 \%$ for $\mathrm{T} 1$

2. It might appear strange that positive emotion expressiveness would be negatively related to gratitude in men $(r=-.13)$. Thus, we examined other correlations with positive emotion expressiveness in men and found a positive relation with trait global positive affect $(r=.27)$ and no relation with trait global negative affect $(r=.01)$. As expected, positive emotion expressiveness is related to the experience of positive emotions, and there is some degree of independence from the experience of negative emotions. However, fitting with our primary thesis, there is something unique about gratitude in men. The operation of gratitude is different than other positive emotions in men. 


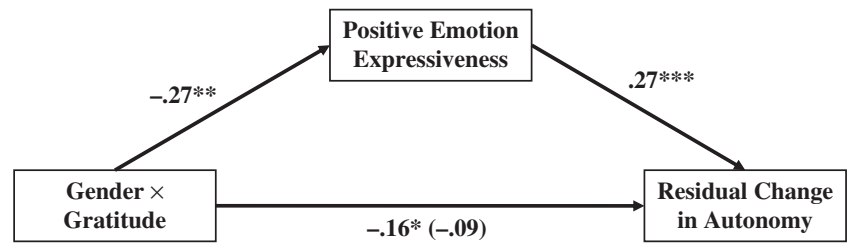

Figure 2

Positive emotional expressiveness as a partial mediator of the Gender $\times$ Gratitude interaction on residual changes in autonomy over a 3-month period. All coefficients are standardized estimates. The criterion variable reflects change in autonomy over the course of the 3 months under study. The beta coefficient in parentheses reflects the effects of Gender $\times$ Gratitude on changes in autonomy controlling for positive emotion expressiveness. $* * p<.01$, *** $p<.001$.

autonomy). The final condition involved demonstrating a significant reduction in the effect of the Gender $\times$ Gratitude interaction on changes in relatedness and autonomy after accounting for variance attributable to positive emotion expressiveness. The Sobel test of mediation (Baron \& Kenny, 1986; MacKinnon, Warsi, \& Dwyer, 1995) was used. A significant Sobel $z$ indicates that the mediator partially accounts for the influence of an independent variable on a dependent variable. Positive emotion expressiveness accounted for the significant Gender $\times$ Gratitude interaction on changes in the satisfaction of relatedness, $z=2.63, p<.01$, and autonomy, $z=2.30$, $p=.02$. These data provide evidence of partial mediation.

\section{Discussion}

Study 3 extended previous findings showing that women thinking about past gifts report greater gratitude and associate the experience with more benefits and fewer costs compared with men. Similar to Study 2, women reported higher scores on a measure of trait gratitude. Additionally, we found evidence that women's and men's dispositional gratitude related differently to aspects of well-being across time. Women derived greater benefits from gratitude, including (1) greater satisfaction of the need to feel connected to and cared for by others (belongingness) and (2) increased feelings of freedom to act in ways that are consistent with core values (autonomy). It is easier to conceptualize why gratitude might foster social relationships and 
relatedness as opposed to autonomy. However, the link with autonomy becomes more apparent when you consider that a central element of gratitude is mindfulness, the act of being aware of sources of goodness present in one's life. This awareness of a benevolent world can be expected to provide a greater sense of confidence to act in an authentic manner with a feeling of autonomy. This fits with other theorists suggesting that mindfulness and acceptance are mechanisms that allow people to effectively live in the present moment, recognize personally important values, and live in accordance with these values as opposed to the controlling values of other people (Hayes, Strosahl, \& Wilson, 1999). Thus, the path from gratitude to autonomy might be a function of mindfulness facets.

Both relatedness and autonomy are considered to be fundamental human needs and are posited as essential in the facilitation of personal growth and happiness, and the repair of emotional disturbances (Deci \& Ryan, 2000). Women seemed to reap more benefits than men from being a grateful person. We found evidence to suggest that the general willingness to be emotionally expressive functions as a mediator of gender differences in relations between gratitude and well-being. In women, trait gratitude was positively related to emotion expressiveness; the opposite effect was found in men. In turn, women derived greater psychological benefits from gratitude as a function of their willingness to share and express emotion experiences with others. A tendency to share grateful experiences might allow women to initiate, maintain, and strengthen relationships by acknowledging and validating the importance of others in their life. Emotion expression might also lead to positive mood contagion, leading others to show a preference for spending more time with grateful individuals. Expressing emotions may encourage mutual social support and facilitate the development of the types of lasting, significant social connections that are at the core of pleasant, engaging, and meaningful living (Argyle, 2001; Diener \& Seligman, 2002). Expressing emotions facilitates the savoring of events, allowing people to recall memories of positive emotional experiences to buffer themselves during times of emotional stress. The willingness to openly express emotion might also provide access to clarifying values and living in accordance with them, satisfying the need for autonomy and not just relatedness. Thus, emotion expressiveness in women appears to be a critical mechanism connecting well-being and gratitude. 
In contrast, there was no support for emotion expressiveness as a mechanism of action in men. These data may be interpreted in several ways. As discussed earlier, women in general are more willing than men to express emotions (Kring \& Gordon, 1998). Men's preference for concealing emotions in general seems culturally proscribed with the expression of gratitude being associated with additional negatively evaluated feelings of vulnerability, dependence, or indebtedness. An unwillingness to be in contact with negatively evaluated emotions may lead to efforts to avoid, conceal, or alter the emotional experience at the expense of other values or psychological benefits (Hayes et al., 1999). Men's preference to avoid feelings of perceived vulnerability or indebtedness costs them opportunities to develop and strengthen relationships with others. These consequences may unintentionally limit the benefits associated with gratitude for men. Interventions designed to increase psychological flexibility (e.g., reduce negative evaluations, generate alternative value consistent appraisals of gratitude) may result in an increase in men's willingness to express feelings of gratitude and, over time, promote psychological well-being. Including these types of add-on modules might enhance the therapeutic utility of gratitude interventions. There are data to show that men are not born less emotionally expressive than women, but in fact the teaching and internalization of socially proscribed gender norms influences the experience, expression, and regulation of specific emotions (Brody, 1997, 1999; Levant \& Kopecky, 1995). These processes tend to be malleable. Thus, there is great promise in examining ways to change how men relate to feelings, thoughts, and behaviors linked to receiving gifts.

We also conducted a conservative test of construct specificity. Relations between gratitude and well-being for women were specific to dispositional gratitude and could not be attributed to global positive or negative affect. This is an important finding, as theories and supportive data suggest that being in a positive mood facilitates a shift in cognitive processing to be more flexible, efficient, and creative, allowing for the availability of greater cognitive resources, physical stamina, and effort toward the pursuit of personally desired outcomes (for reviews, see Carver, 2003; Fredrickson, 1998; Isen, 2000). Habitual tendencies to experience positive affect have a number of observable benefits (Lyubomirsky, King, \& Diener, 2005). This study provides evidence for studying differences among discrete 
affects, with an emphasis on the uniqueness of gratitude (and unequal benefits for women and men).

An alternative explanation for our results is that women experience greater fluctuations in the satisfaction of basic psychological needs compared with men. Moreover, interpersonal events (receiving gifts) may exert a stronger influence on feelings of autonomy and relatedness for women than men. This line of inquiry can be addressed in future empirical investigations.

\section{GENERAL DISCUSSION}

Across three studies with varying methodologies, our data suggest that women compared with men show evidence of a more grateful disposition and derive greater benefits from the experience and expression of gratitude. We found several mechanisms that explain this relation, including women's tendencies to hold more positive appraisals about the benefits of gratitude; men's tendencies to view gratitude as more challenging, anxiety provoking, and burdensome; and women's greater willingness to openly express emotions and view this as an effective regulatory act. We showed a high degree of specificity, as there was no evidence of gender differences in appraisals for other intimate social behaviors and findings could not be attributed to global positive and negative affect.

Based on the available evidence, gratitude is one of the strongest contributors to well-being, and our data suggest that women are in a more favorable position to benefit. As a moral motivator, gratitude encourages prosocial behavior in the beneficiary either directly toward the benefactor or others. Therefore, compared with men, women are more likely to be altruistic and help out others, both of which promote deep and broad social ties. Consequently, to the degree that gratitude encourages such behavior, women increase their chances for well-being because the presence of strong social relationships is perhaps the single greatest cause of happiness (Argyle, 2001; Diener \& Seligman, 2002). As a moral reinforcer, gratitude increases the probability that the benefactor will act prosocially toward the beneficiary in the future. Women reported experiencing greater gratitude. Thus, women compared with men are more likely to receive additional benefits - be it in the form of material possessions or nurturing relationships-from the benefactor yet again. These resources will accrue over time and be a valuable reserve to tap 
into when needed, thus promoting psychological resiliency. Also, gratitude is a "hard-to-fake signal" of cooperation, which includes the character strengths of honesty, trustworthiness, and integrity. In the simplest terms, gratitude signals to others in the group which people are genuine cooperators (as opposed to free riders). Therefore, people who more effectively experience and express gratitudeand our studies collectively suggest these people would probably be women - are more likely to enjoy cooperative exchanges (Emmons \& McNamara, 2006). Taken together, our data indicate that women compared with men are at an advantage to reap more benefits - such as personal and relational well-being, social capital, and physical resources - from the experience and expression of gratitude.

Several limitations are noted. First, the effect sizes are small to moderate for gender differences. But we argue that this is important given the potency of gratitude on psychological well-being and evidence that interventions targeting gratitude outperform other techniques designed to explicitly enhance full healthy functioning (and not the alleviation of particular symptoms or disorders; Seligman et al., 2005). The magnitude of change in gratitude from gender differences should not be viewed as inconsequential, given the multitude of influences on naturally occurring affect and well-being; our effect sizes also are of similar magnitude to comparable studies. It is also important because asking for help and relying on other people is part of navigating the everyday hassles and major stressors of modern life with some semblance of health. Research shows that men are less likely to seek help from friends, family, or medical professionals due to fears of being evaluated negatively and the embarrassment of being dependent on others (George \& Fleming, 2004; Good, Dell, \& Mintz, 1998). Appraisals about being the recipient of gifts from other people and the expression of gratitude can have real health consequences, such as failing to engage in health promotion behaviors (e.g., seeking therapy and medical examinations when needed). Second, we addressed gender identity (i.e., identifying oneself as a man or a woman) but not gender roles (i.e., masculine ideology). Similar to the findings of Bruch et al. (1998), we may have found enhanced gender differences in gratitude if we had measured gender roles. Third, in each of our samples, women consistently outnumbered men (roughly 2 to 1 ). Because we used an open recruitment approach for each study, concerns might be raised that the men in the psychology courses and community group might possess limited 
generalizability. Different gender effects might be found in less educated and affluent samples. We suspect that less educated and affluent samples would be more reliant on stereotypical gender norms and roles and, thus, lead to even more pronounced gender differences than those found in the current set of studies (Simon \& Nath, 2004). Along these same lines, in Study 2, our recruitment strategy for older and younger adults differed, and motivations for participation serve as a relevant confound in our ability to interpret age-related findings. Fourth, despite a number of tests of construct specificity, we did not conduct comparisons between gratitude and other discrete affects. Studies are needed to further evaluate the boundary conditions of where men and women converge and diverge in various facets of emotions and social activity. Finally, we did not address heterogeneity within men and women or the individual differences underlying gender differences in gratitude. Had we done this, we think larger effects would have surfaced.

Some insight was gained about gender differences and positive outcomes among younger and older adults about their experience and expression of gratitude. The literature classifies gratitude as a positive emotion or strength, and gratitude interventions show impressive potency. Our three studies suggest the need to remain sensitive to potential gender differences in basic and applied research. Questions remain, however, as to whether additional important individual difference variables influence the degree to which gratitude is viewed positively, willing to be expressed, and associated with well-being. Women evaluated the expression of gratitude more positively and as less challenging, experienced more intense gratitude in their everyday life, and perceived less costs associated with receiving gifts compared with men. Women were also more likely to possess grateful dispositions, and those who did found or created greater well-being in their lives over time compared with men. Given these findings, gender is clearly an important diversity issue in gratitude research and practice, and future applied gratitude work should consider how to address barriers to benefits with adjunct intervention modules.

\section{REFERENCES}

Aiken, L. S., \& West, S. G. (1991). Multiple regression: Testing and interpreting interactions. London: Sage.

Argyle, M. (2001). The psychology of happiness. New York: Taylor and Francis Inc. 
Baron, R. M., \& Kenny, D. A. (1986). The moderator-mediator variable distinction in social psychological research: Conceptual, strategic, and statistical considerations. Journal of Personality and Social Psychology, 51, 1173-1182.

Bartlett, M. Y., \& DeSteno, D. (2006). Gratitude and prosocial behavior: Helping when it costs you. Psychological Science, 17, 319-325.

Barrett, L. F., Lane, R. D., Sechrest, L., \& Schwartz, G. E. (2000). Sex differences in emotional awareness. Personality and Social Psychology Bulletin, 26, 1027-1035.

Baumeister, R., \& Leary, M. R. (1995). The need to belong: Desire for interpersonal attachments as a fundamental human motivation. Psychological Bulletin, 117, 497-529.

Baumgarten-Tramer, F. (1938). "Gratefulness" in children and young people. The Journal of Genetic Psychology, 53, 53-56.

Berlyne, D. E. (1960). Conflict, arousal, and curiosity. New York: McGraw Hill.

Brody, L. R. (1997). Gender and emotion: Beyond stereotypes. Journal of Social Issues, 53, 369-394.

Brody, L. R. (1999). Gender, emotion, and the family. Cambridge, MA: Harvard University Press.

Bruch, M. A., Berko, E., \& Haase, R. F. (1998). Shyness, masculine ideology, physical attractiveness, and emotional inexpressiveness: Testing a mediational model of men's interpersonal competence. Journal of Counseling Psychology, 45, 84-97.

Carstensen, L. L., Gross, J., \& Fung, H. (1997). The social context of emotion. Annual Review of Geriatrics and Gerontology, 17, 325-352.

Carstensen, L. L., Isaacowitz, D., \& Charles, S.T (1999). Taking time seriously: A theory of socioemotional selectivity. American Psychologist, 54, 165-181.

Carver, C. S. (2003). Pleasure as a sign you can attend to something else: Placing positive feelings within a general model of affect. Cognition and Emotion, 17, 241-261.

Charles, S. T., \& Carstensen, L. L. (2007). Emotion regulation and aging. In J. J. Gross (Ed.), Handbook of emotion regulation (pp. 307-327). New York: Guilford Press.

Ciarrochi, J., Hynes, K., \& Crittenden, N. (2005). Can men do better if they try harder: Sex and motivational effects on emotional awareness. Cognition and Emotion, 19, 133-141.

Deci, E. L., Guardia, J., Moller, A., Scheiner, M., \& Ryan, R. (2006). On the benefits of giving as well as receiving autonomy support: Mutuality in close friendships. Personality and Social Psychology Bulletin, 32, 313-327.

Deci, E. L., \& Ryan, R. M. (1985). Intrinsic motivation and self-determination in human behavior. New York: Plenum.

Deci, E. L., \& Ryan, R. M. (2000). "The "what" and "why" of goal pursuits: Human needs and the self-determination of behavior. Psychological Inquiry, 11, 227-268.

Diener, E., \& Seligman, M. E. P. (2002). Very happy people. Psychological Science, 13, 80-83.

Dindia, K., \& Allen, M. (1992). Sex differences in self-disclosure: A meta-analysis. Psychological Bulletin, 112, 106-124. 
Eagley, A. H., \& Crowley, M. (1986). Gender and helping behavior: A metaanalytic review of the social psychological literature. Psychological Bulletin, 100, 283-308.

Emmons, R. A. (2004). Gratitude. In M. E. P. Seligman \& C. Peterson (Eds.), The VIA taxonomy of human strengths and virtues (pp. 553-568). New York: Oxford University Press.

Emmons, R. A., \& McCullough, M. E. (2004). The psychology of gratitude. New York: Oxford University Press.

Emmons, R. A., \& McNamara, P. (2006). Sacred emotions and affective neuroscience: Gratitude, costly signaling, and the brain. In P. McNamara (Ed.), Where God and science meet: How brain and evolutionary studies alter our understanding of religion (pp. 27-46). Westport, CT: Praeger Publishers.

Fehr, B. (1996). Friendship processes. Thousand Oaks, CA: Sage.

Fischer, A. H. (1993). Sex differences in emotionality: Fact or stereotype? Feminism and Psychology, 3, 303-318.

Fredrickson, B. L. (1998). What good are positive emotions? Review of General Psychology, 2, 300-319.

Fredrickson, B. L. (2004). Gratitude, like other positive emotions, broadens and builds. In R. A. Emmons \& M. E. McCullough (Eds.), The psychology of gratitude (pp. 145-161). New York: Oxford University Press.

Fujita, F., Diener, E., \& Sandvik, E. (1991). Gender differences in negative affect and well being: The case for emotional intensity. Journal of Personality and Social Psychology, 61, 427-434.

Gagné, M. (2003). The role of autonomy support and autonomy orientation in prosocial behavior engagement. Motivation and Emotion, 27, 199-223.

George, A., \& Fleming, P. (2004). Factors affecting men's help-seeking in the early detection of prostate cancer: Implications for health promotion. Journal of Men's Health and Gender, 1, 345-352.

Good, G. E., Dell, D. M., \& Mintz, L. B. (1998). Male role and gender role conflict: Relations to help seeking in men. Journal of Counseling Psychology, 36, 295-300.

Gordon, A. K., Musher-Eizenman, D. R., Holub, S. C., \& Dalrymple, J. (2004). What are children thankful for? An archival analysis of gratitude before and after the attacks of September 11. Journal of Applied Developmental Psychology, 25, 541-533.

Gross, J. J., \& John, O. P. (1995). Facets of emotional expressivity: Three selfreport factors and their correlates. Personality and Individual Differences, 19, 555-568.

Gross, J. J., \& John, O. P. (1997). Revealing feelings: Facets of emotional expressivity in self reports, peer ratings, and behavior. Journal of Personality and Social Psychology, 72, 435-448.

Gross, J. J., \& John, O. P. (1998). Mapping the domain of expressivity: Multimethod evidence for a hierarchical model. Journal of Personality and Social Psychology, 74, 170-191.

Grossman, M., \& Wood, W. (1993). Sex differences in intensity of emotional experience. Journal of Personality and Social Psychology, 65, 1010-1022. 
Hayes, S. C., Strosahl, K., \& Wilson, K. G. (1999). Acceptance and Commitment Therapy: An experiential approach to behavior change. New York: Guilford Press.

Ilardi, B. C., Leone, D., Kasser, R., \& Ryan, R. M. (1993). Employee and supervisor ratings of motivation: Main effects and discrepancies associated with job satisfaction and adjustment in a factory setting. Journal of Applied Social Psychology, 23, 1789-1805.

Ingoldsby, B. B., Horlacher, G. T., Schvaneveldt, P. L., \& Matthews, M. (2005). Emotional expressiveness and martial adjustment in Ecuador. Marriage and Family Review, 38, 25-44.

Isen, A. M. (2000). Positive affect and decision making. In M. Lewis \& J. Haviland-Jones, Handbook of emotions (2nd ed., pp. 417-435). New York: Guilford.

Kashdan, T. B., \& Breen, W. E. (2007). Materialism and diminished well-being: Experiential avoidance as a mediating mechanism. Journal of Social and Clinical Psychology, 26, 521-539.

Kelly, J. R., \& Hutson, S. L. (1999). Gender-emotion stereotypes are context specific. Sex Roles, 40, 107-120.

Krause, N. (2006). Gratitude toward God, stress, and health in late life. Research on Aging, 28, 163-183.

Kring, A. M., \& Gordon, A. H. (1998). Sex differences in emotion: Expression, experience, and physiology. Journal of Personality and Social Psychology, 74, 686-703.

La Guardia, J. G., Ryan, R. M., Couchman, C. E., \& Deci, E. L. (2000). Withinperson variation in security of attachment: A self-determination theory perspective on attachment, need fulfillment, and well-being. Journal of Personality and Social Psychology, 79, 367-384.

Lazarus, R. S. (1991). Emotion and adaptation. New York: Oxford University Press.

Levant, R. F., \& Kopecky, G. (1995). Masculinity, reconstructed. New York: Dutton.

Lyubomirsky, S., King, L. A., \& Diener, E. (2005). The benefits of frequent positive affect. Psychological Bulletin, 131, 803-855.

MacKinnon, D. P., Warsi, G., \& Dwyer, J. H. (1995). A simulation study of mediated effect measures. Multivariate Behavioral Research, 30, 41-62.

McAdams, D. P. (2001). The psychology of life stories. Review of General Psychology, 5, 100-122.

McCullough, M. E., Emmons, R. A., \& Tsang, J. (2002). The grateful disposition: A conceptual and empirical topography. Journal of Personality and Social Psychology, 82, 112-127.

McCullough, M. E., Kilpatrick, S. D., Emmons, R. A., \& Larson, D. B. (2001). Is gratitude a moral affect? Psychological Bulletin, 127, 249-266.

McCullough, M. E., \& Tsang, J. (2004). Parent of the virtues? The prosocial contours of gratitude. In R. A. Emmons \& M. E. McCullough (Eds.), The psychology of gratitude (pp. 123-144). New York: Oxford University Press.

McCullough, M. E., Tsang, J., \& Emmons, R. A. (2004). Gratitude in intermediate affective terrain: Links of grateful moods to individual differences and 
daily emotional experience. Journal of Personality and Social Psychology, 86, 295-309.

Naito, T., Wangwan, J., \& Tani, M. (2005). Gratitude in university students in Japan and Thailand. Journal of Cross Cultural Psychology, 36, 247-263.

Nowak, M. A., \& Roch, S. (2007). Upstream reciprocity and the evolution of gratitude. Proceedings of the Royal Society B, 274, 605-609.

Pleck, J. H. (1981). The myth of masculinity. Cambridge, MA: MIT Press.

Reis, H. T. (1998). Gender differences in intimacy and related behaviors: Context and process. In D. J. Canary \& K. Dindia (Eds.), Sex differences and similarities in communication: Critical essays and empirical investigations of sex and gender in interaction (pp. 203-231). Mahwah, NJ: Erlbaum.

Scherer, K., Wallbott, H., \& Summerfield, A. (1986). Experiencing emotion: A cross-cultural study. Cambridge, UK: Cambridge University Press.

Schwartz, S. H., \& Rubel, T. (2005). Sex differences in value priorities: Crosscultural and multimethod studies. Journal of Personality and Social Psychology, 89, 1010-1028.

Seligman, M. E. P., Steen, T. A., Park, N., \& Peterson, C. (2005). Positive psychology progress: Empirical validation of interventions. American Psychologist, 60, 410-421.

Simon, R. W., \& Nath, L. E. (2004). Gender and emotion in the United States: Do men and women differ in self reports of feelings or expressive behavior? American Journal of Sociology, 109, 1137-1176.

Solomon, R. C. (1995). The cross-cultural comparison of emotion. In J. Marks \& R. T. Ames (Eds.), Emotions in Asian thought (pp. 253-294). Albany: State University of New York Press.

Sommers, S. (1984). Interpersonal affect in early and mid-adulthood. Paper presented at the Second International Conference on Personal Relationship, Madison, WI.

Sommers, S., \& Kosmitzki, C. (1988). Emotion and social context: An AmericanGerman comparison. British Journal of Social Psychology, 27, 35-49.

Steger, M. F., Kashdan, T. B., \& Oishi, S. (2008). Being good by doing good: Daily eudaimonic activity and well-being. Journal of Research in Personality, 42, 22-42.

Stoppard, J. M., \& Gruchy, C. (1993). Gender, context, and expression of positive emotion. Personality and Social Psychology Bulletin, 19, 143-150.

Taylor, S. E., Klein, L. C., Lewis, B. P., Gruenwald, T. L., Gurung, R. A. R., \& Updegraff, J. A. (2000). Biobehavioral responses to stress in females: Tendand-befriend, not fight-or-flight. Psychological Review, 107, 411-429.

Tesser, A., Gatewood, R., \& Driver, M. (1968). Some determinants of gratitude. Journal of Personality and Social Psychology, 9, 233-236.

Timmers, M., Fischer, A. H., \& Manstead, A. S. R. (1998). Gender differences in motives for regulating emotions. Personality and Social Psychology Bulletin, 24, 974-985.

Trivers, R. L. (1971). The evolution of reciprocal altruism. Quarterly Review of Biology, 46, 35-57.

Tsang, J. (2006). Gratitude and prosocial behavior: An experimental test of gratitude. Cognition and Emotion, 20, 138-148. 
Tsang, J. (2007). Gratitude for small and large favors: A behavioral test. Journal of Positive Psychology, 3, 157-167.

Ventimiglia, J. C. (1982). Sex roles and chivalry: Some conditions of gratitude to altruism. Sex Roles, 8, 1107-1122.

Watson, D. (2000). Mood and temperament. New York: Guilford Press.

Watson, D., Clark, L. A., \& Tellegen, A. (1988). Development and validation of brief measures of positive and negative affect: The PANAS. Journal of Personality and Social Psychology, 54, 1063-1070.

Weiner, B. (1985). An attributional theory of achievement motivation and emotion. Psychological Review, 92, 548-573. 